\title{
CONCEPTUAL MODEL FOR THE REPLACEMENT OF THE HORN OF A PHONOGRAPH OF XIXth CENTURY
}

\author{
Beatriz Marin ${ }^{1}$, José Antonio Madrid García ${ }^{1}$ and Maria Carmen Bachiller ${ }^{2}$ \\ ${ }^{1}$ Laboratorio de Documentación y Registro, Instituto Universitario para la restauración del Patrimonio, \\ Universitat Politècnica de València, València, Spain; \\ ${ }^{2}$ Instituto Universitario de Telecomunicación y Aplicaciones Multimedia, \\ Universitat Politècnica de València, València, Spain
}

\begin{abstract}
$3 D$ printing of missing parts of a cultural heritage artefact opens many possibilities and extends the challenges in the processes of intervention on cultural heritage assets. However, restoring these objects may not only mean the replacement of a shortage from its aesthetic point of view, but restoring the function for which they were created. In these processes the replica of the object must be exact and of quality, but also specific.

In this sense, the presented work is a multidisciplinary attempt to reproduce the missing horn of a phonograph, dated on the late $19^{\text {th }}$ Century. This phonograph belongs to the collection of the 'Vicente Miralles Segarra' Telecommunication Museum of the Universitat Politècnica de València. The objective was to recover its aesthetic, didactic and functional levels, i.e restoring its ability to emit sound. To this end, several models were printed with different materials, and the quality of the recorded sound with the different horns was evaluated, assessing their similarity to that obtained from an original horn.
\end{abstract}

Keywords: 3D printing, acoustic assessment, cultural heritage restoration, non-destructive analysis, rapid prototyping.

\section{INTRODUCTION [heading]}

The purpose of this paper is to describe the methodology employed for the physical reconstruction of a missing part of a 19th Century phonograph. The methodology includes the development and manufacture of the prototype using 3D scanning, computer-aided design (CAD) and 3D printing. This type of proof of concept, as explained by Fantini et al. (2008), helps to understand the capacity, and limitations of technology.

$3 \mathrm{D}$ printing is a non-invasive and reversible method for improving the restoration process. Currently this manufacturing technique and more recently, the appearance of low cost printing devices make this technology redily available, and has been presented as a solution for the production of small-scale objects (Alemanno, 2014; 145).

However, the challenge posed in this research is more complex. The traditional conservation and restoration approaches for the intervention of cultural objects are reviewed under the criteria raised by Brandi $(1988 ; 16)$, those of respect, reversibility and recognition. In addition, the adequacy of the material used to print the prototype has been assessed, as well as whether the addition of other materials can supplant the original part. The work undertaken here was focussed on returning original functionability rather than on simulating appearance alone.

When performing treatments on artifacts of an industrial nature, comparing a quality replica copy against a specific accurate copy should be much more extensive especially when considering the artefact in question which has museographic expectations that must not be ignored (Styliani et al, 2009).

This goal is not only reached with a more or less aesthetic representation, but by encorporating all the values that the object stores and presents (Riegl, 1999 [1903]). In this sense, the notion of artistic value exposed by Riegl at the beginning of the $20^{\text {th }}$ Century is more complex and is closely related to his concept of Kunstwollen (Brassi, 2007). In Kunstwollen theory, the will of a cultural artifact resides on a notion of relative and changing art, which is specific to each period of History (Arrhenius, 2003; 54). Riegl, who had a multidisciplinary background as curator of museums, professor and curator of monuments, was linked to the arts and crafts production and has become a reference for current preservation processes. (Pop, 2015)

The different values of a heritage object not only focus on its value of antiquity, or its instrumental value, but also on how this object is a reference for the historical understanding of that objects' place within a collection. Returning to the statement by Aloïs Riegl, every object becomes a piece of interest for many scholars, or researchers, attending to each one of the aspects that it comprises. (Riegl, 1999: 30-31, 73)

The abovementioned idea is the theoretical framework for the reconstruction of the horn of the phonograph (invented by Thomas A. Edison in 1887) from the collection at the Museum of Telecommunication 'Vicente Miralles Segarra', of the Universidad Politècnica de València. The Museum has another 
similar phonograph that was used as a model to complete the missing part and restore its functionality. (Figure 1)

The objective in reproducing a replacement part was to restore all its values, including visual and functional. The paradox of restoring or repairing is present in the current interventions of objects considered as industrial, since the object must not only look like the original but also perform like the original. (Muñoz, 2003; 37)

Therefore, the capacity to emit accurate sound again and to evaluate the material used for the replacement of the missing component (figure 2) are part of this functional content. In this way, the material for the creation of the prototype can affect both its aesthetic and sound reproduction.

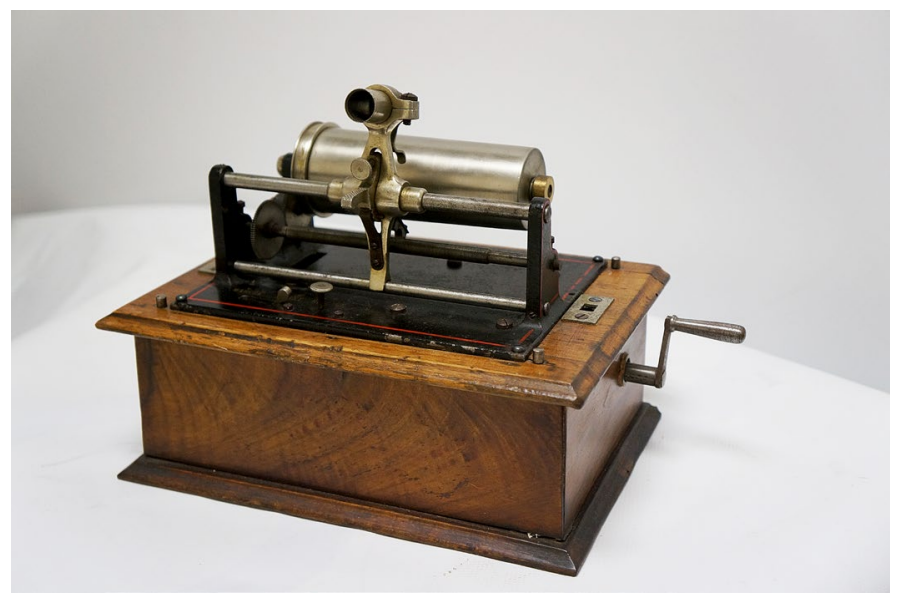

Figure 1. The phonograph.

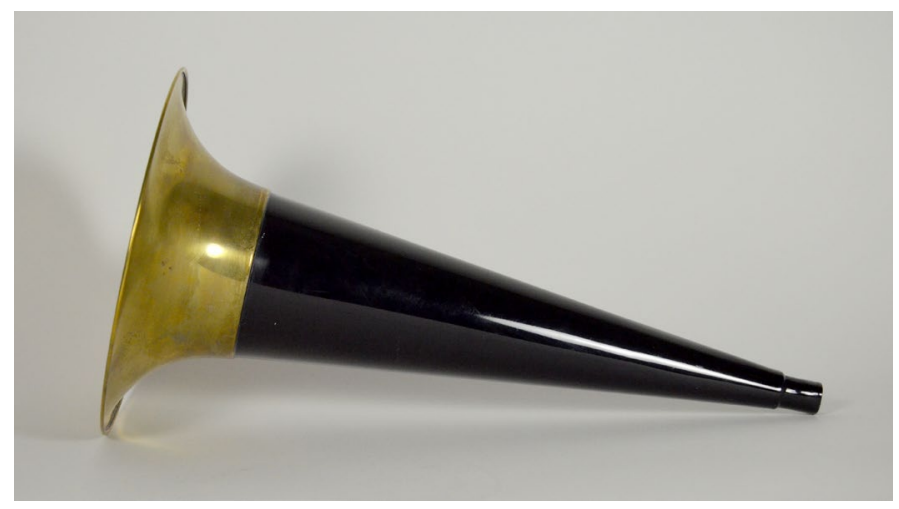

Figure 2. The horn.

Moreover, 3D prototyping appears as an alternative to traditional industrial manufacturing techniques (such as casting, injection molding or milling), which are affordable for mediumor large-scale productions, but inefficient for a single object (Scopigno, 2017; 6).

This paper focuses on the evaluation of the physical behavior of a $3 \mathrm{D}$ printed prototype and its suitability to impersonate the original. The achievement of this objective requires multidisciplinary methodologies addressing the following issues:

(i) the meaning and recognition of the cultural object as a container of a multitude of values within its museum scope, (ii) the study of the part to be substituted, and

(iii) the analysis of its acoustics through the comparison between an original sound record and those obtained in the proof of concept. This last aspect is the main motivation of this work, which combines a team of researchers in $3 \mathrm{D}$ modelling and printing, sound processing and computer science.

Currently, many proofs of this multidisciplinary approach can be found in research dealing with physical models (Scopigno, 2017). Physical models focus on the approach to the manufacturing of real model from its most external or synthetic perspective (Matusik, 2009. Levin, 2013. Papas, 2013. Weyrich, 2009). There are also studies on the performance of current printing devices (Haśan, 2010. Lan, 2013. Rouiller, 2009) or new color application systems (Panozzo, 2015. Zhang, 2015).

Furthermore, some studies have undertaken projects that more closly resemble what we propose and go beyond the physical models of the archaeo-anthropological framework. One example is the 3D reconstruction of fragile bone, allowing for more detailed study without the risk of damaging the original artifacts (D'Urso et al., 2000; Zhang et al., 2000; Pérès et al., 2004). There are also examples within the field of music, as with the recovery of old or modern instruments, conserving their performance (Zoran, 2011. Koumartzis, 2015), or research addressing the possibilities of reversible and non-invasive processes on cultural objects (Pitzalis, 2008).

The structure of the document is organized as follows. The first section describes the case study, along with its characteristics and particularities. In the second section, the process of elaboration of the proof of concept is presented. This section discuss the method of scanning and digitalizing the original model, the $3 \mathrm{D}$ printing process and the selection of materials, as well as the sound tests made to the replicas. The results of the obtained sound tests are described in the last section, before presenting the conclusions of the study.

\section{CASE STUDY}

The object for the case study belongs to the collection located in the 'Vicente Miralles Segarra' Telecommunication Museum of the Higher Technical School of Telecommunication Engineers (ETSIT) at the Universitat Politècnica de València. This collection presents the History of Telecommunication through more than 350 objects of telegraphy, telephony, audiovisual equipment, radiocommunication and instrumentation of the $19^{\text {th }}$ and $20^{\text {th }}$ Centuries (Bachiller, 2016).

Along with maintaining and preserving the collection, the Museum aims to recover the aesthetic, physical and functional aspects of the objects in the collection (Simon, 2010. Levent, 2014). With this in mine, two two phonographs, one of them complete and the other missing its horn were identified in the collection. The invention of the phonograph constituted an authentic technological revolution, since it was the first device capable of recording and reproducing the human voice. 
The phonograph (figure 3 ) is composed of a box or base (1) in which the reproduction and recording system is located. This system has a manual crank (2) that turns the gears and lathes. On the main winch (3) a wax roll is inserted, which is the support that contains the audio. The diaphragm needle (4) rubs the groves of the wax roll emitting vibrations through the membrane that amplifies the sound towards the horn (5). Without each of these parts, the phonograph is unable to function.

Therefore, the aim of the horn, with its conical shape, is to receive and propagate the sound waves that are collected or emitted from the needle on the membrane, which fulfills the function of diaphragm. The horn amplifies both the vibration caused by the sound waves in recording, and the vibration caused by the grooves on the wax cylinder in reproduction. All this indicates that the horn is a characteristic and fundamental part of the phonograph, in which not only the aesthetic value is involved.

Figure 3. Sketch of the general parts that compose a phonograph; box or base (1), manual crank (2), main winch (3), diaphragm (4), and horn (5).

\section{MATERIALS AND METHODS}

The creation of the prototype was subdivided into three stages: the acquisition of data for the elaboration of the $3 \mathrm{D}$ model, the manufacturing using 3D printing and finally the comparison of the acoustic response of the prototype with the response of the original device.

It is true that the prototype does not have much geometric complexity; nevertheless, for the design of the model, it was decided to scan one original with laser scanning techniques instead of using traditional 3D computer-aided design (CAD) modeling tools. This decision was taken because scanning offers a more precise approach to the original model (Fantini, 2008). In the developed conceptual model, there are small details of the surface that can not be directly replicated by a numerical solution.

\section{Data acquisition by means of 3D laser scanner}

In this first step of digital reconstruction, a Next Engine ${ }^{\circledR}$ 3D laser scanner was used. This scanner uses a triangulation system that does not require contact with the object. Since the original horn was made of brass, the metal reflected light, not allowing a proper scanning process. These metal parts generated reading errors. This problem was solved by interposing a layer of Japanese paper of 29 gr of thickness on these areas to decrease its reflexion index, thus obtaining a surface with greater opacity.

The application of this paper was with a brush moist with water. When the paper layer dries, it creates a homogeneous surface with a negligible thickness on the model. The application of this layer of paper is a method that ensures total reversibility in both the application phase and the phase of elimination. This method avoids the use of chemical products that reduce the reflection effect of the shiny surface, since they are not suitable for application on cultural heritage assests (Celani, 2009). Likewise, the original material of the horn does not suffer any type of alteration due to the contribution of humidity in this method.

The solution adopted for the elaboration of the internal surface was to measure the thickness of the original horn and to extrapolate it to the symmetry of the internal contour line. In this way, the triangular mesh of the whole form was completed. The resulting model was exported to an OBJ format from the AutoDesk 3DS Max® 2016. (Figure 4)

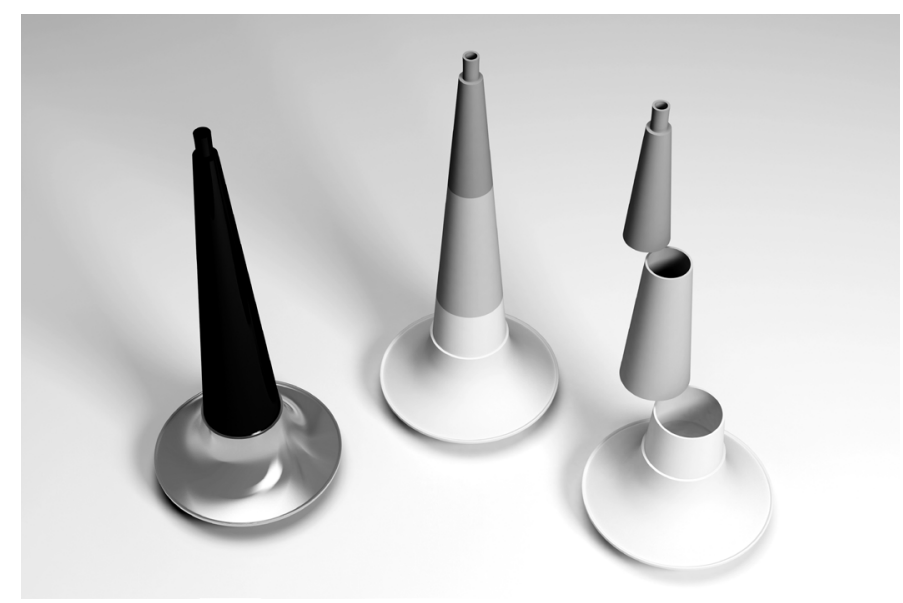

Figure 4. 3D mesh of the horn.

In the modeling stage, it was necessary to soften the vertices of the triangular mesh to eliminate the noise of the image that was produced during the capture of the real object (Scopigno, 2005). Therefore, the file was imported into specific software for its treatment, 3DS Max ${ }^{\circledR} 2016$, maintaining the vectoring system of the final mesh without altering the forms or measurements.

\section{D printing}

For the elaboration of the prototype a system of Fused Deposition Modeling (FDM) was used. This is one of the most common printing systems and, as Scopigno indicates, the vast majority of 'low cost 3D printing devices' in the last 10 years are based on these additive techniques. This technique is not only economic, but also easy of use, and it produces suitable quality items with good precision compared to the other additive techniques (Scopigno, 2017; 9-10). However, the main reason that led to the choice of FDM, as a 3D printing system, was that it enables the use of a wide range of printing materials, including those with additives. 
The selected printer for this process was Hephestos $2 \AA$ model 2016, from BQ, due to its characteristics of self-calibration, sufficient printing area and easiness of handling. Moreover, it allows the use of a wide variety of materials compared to other current low-cost solutions in the market.

With the use of the Hephestos2® printer, as a Cartesian 3D printer, the problem was the limitation in terms of the dimensions of the piece to be reproduced, compared to Delta 3D printers that allow larger objects.

The maximum sizes of the horn are $180 \times 180 \times 401 \mathrm{~mm}$. These sizes exceeded the height dimension of the printing volume of the printer, which only supports a volume of $210 \times 297 \times$ $220 \mathrm{~mm}$. This height limitation meant that we had to fragment the model into three bodies to get the size of the original horn. In relation to the ' $z$ ' axis of the composition, the three bodies had a height of $117 \mathrm{~mm} \mathrm{(a),} 142 \mathrm{~mm}$ (b) and $142 \mathrm{~mm}$ (c) respectively.

The last part of the process of reproduction of the piece was the configuration of the printing parameters. The software Ultimaker Cura ${ }^{\circledR}$ (V. 2.1.2.) was used for this. The software allows customizing the $3 \mathrm{D}$ printing profile to obtain the desired quality.

The printing time of the different models ranged between 9 and $12 \mathrm{~h}$, depending on the material and quality used for printing. This object was exported to GCODE format so that the 3D printer could recognize both the final model and the printing profile.

\section{Printing materials [sub-heading]}

At this point, the decision focused on the choice of the printing material. This choice was important to evaluate the sound recordings of the manufactured prototypes against the original one. In this case, the materials for printing and testing were reduced to the PLA (Poly Lactic Acid) compounds and ABS (Acrylonitrile Butadiene Styrene), which is the other benchmark in the market.

The prototype with ABS were expensive and complex, due to the initial deformation that it presented due to the lack of adhesion in the first layers, which required a headed bed for printing to avoid the warping effect. Something very different from what happened with the prototypes in PLA, which does not need so much temperature to make the coil cable flow and therefore hardens more quickly, increasing the junction in the manufacture of layer on layer. Nevertheless, the characteristic that underlies the choice of the PLA was not only that it does not emit harmful gases, but that in its filament a secondary material can be added to the main support, as we have already mentioned. (Figure 5)

After the initial assessment, several definitive samples were carried out with the original size of the horn, both in ABS and in PLA. These samples were printed in the same way, already exposed in the previous point, with filaments of $1.75 \mathrm{~mm}$ of diameter from the company ColorFabb ${ }^{\circledR}$. In each case, a scale replica of the original horn was obtained; three bodies that were adhered using glue built the replica.

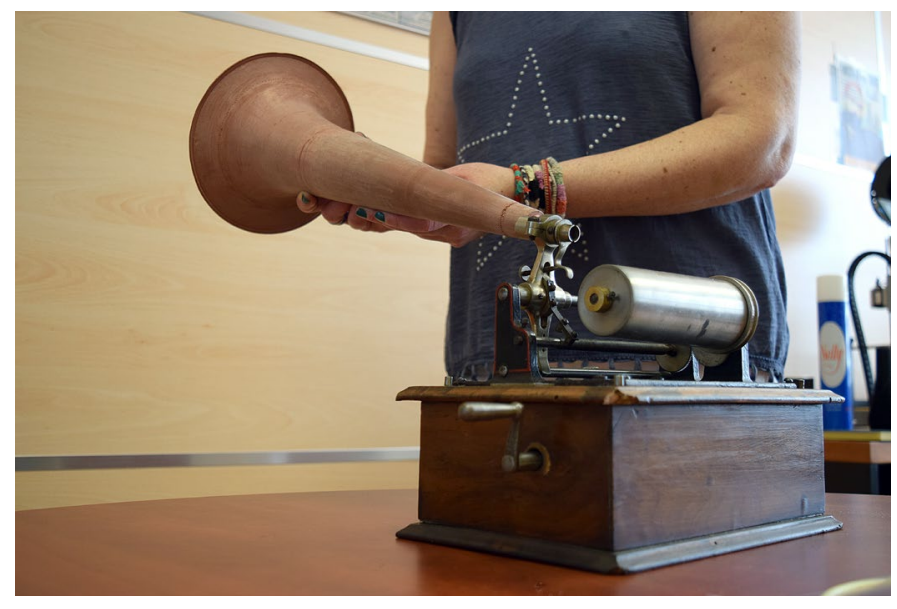

Figure 5. Printed proof of missing part.

For the acoustic evaluation, the results that most closely approximate the original sound are presented, as:

- PLA + 00. The material of this first sample did not have any type of additive. Black filament was used (Standard black RAL 9005)

- PLA + Bronze. The filament used had a composition of $20 \%$ metal particles and $80 \%$ PLA. For this sample, the colorFabb bronzeFill - PLA / PHA + fine bronze powder filament (KTA2014 / 048) was used.

- $\quad$ PLA + Copper. As in the previous case, the filament had a composition of $20 \%$ metal particles and $80 \%$ PLA. In this case the filament was colorFabb copperFill - PLA / PHA + fine copper powder (KTA2014 / 207).

- ABS. This material is pure ABS, yellow filament (COL3DLFD003Y) of the company COLIDO 3D.

\section{Acoustic assessment}

The final stage was to evaluate which horn was the most suitable, based on the printed samples obtained, according to the material used. All acoustic evaluations were made under the same conditions and with the same devices: same microphones and in the same position, same recording studio, same gramophone and needle as well as same ambient soundscape. In this way, in this proof of concept, it was assured that the possible variables that might have influenced the recordings have been the same.

According to the study conducted in (Moles, 2016), the following characteristics are common to all phonograph recordings and should be taken into account when performing sound tests with a phonograph:

- Mono recording. Since it was not until 1930 when recording in stereo was patented.

- $\quad$ Flutter. Because the speed of rotation of the cylinder of the phonograph is not perfectly constant, causing a small modulation in frequency that produces the Flutter. This effect causes certain randomness and slight metallization of the sound. 
- Amplitude distortion. In a phonograph record the amplitude richness is randomly limited.

- Band pass filtering. The limitation on the main bandwidth of the phonograph is given by the recording support, but also by the response of the speakers that were used jointly with the phonograph. In this way, the response used to be good in the range of 400 to $2000 \mathrm{~Hz}$.

Periodic Noise. The phonograph mechanism to rotate the cylinder and, consequently, to make the needle rub its surface, is formed by gears and tapes. This mechanism produces a periodic noise.

The tests were aimed to assess, in a comparative way, the audio compiled by the use of an original horn against the audio reproduced by the $3 \mathrm{D}$ printed horns.

For audio recording, a measurement microphone from Earthworks ${ }^{\circledR}$ model M30 HDM was used. The microphone assures flat frequency response in the range of $5 \mathrm{~Hz}$ to $30 \mathrm{kHz}$, with omnidirectional polar pattern and handles up to $140 \mathrm{~dB}$ SPL without distortion. In the ETSIT Recording Studio, a Presonos audio card and two audio processing software packages, Audacity ${ }^{\circledR}$ 2.2.1 and Sound Forge ${ }^{\circledR}$ Pro 11.0.299, were used.

The digital files, in $\mathrm{WAB}$ format, obtained in each case, were studied through the possibilities offered by the audio software Audacity ${ }^{\circledR}$. This program allows the comparison of the different sound records, both in the time domain and in the frequency spectrum. This comparison offers both the fundamental frequencies of the sound and the harmonics that accompany them. The study of the temporal domain enables the comparison of amplitudes and waveforms of the acoustic signal. While the study of the frequency spectrum can show the frequencies that have disappeared in the printed tests against of the frequencies of the original record. This comparative study provides a clearer idea of how the bandwidth of the signals has varied, as well as the characteristic harmonics that accompany and complete the studied sound record. (Figure 6)

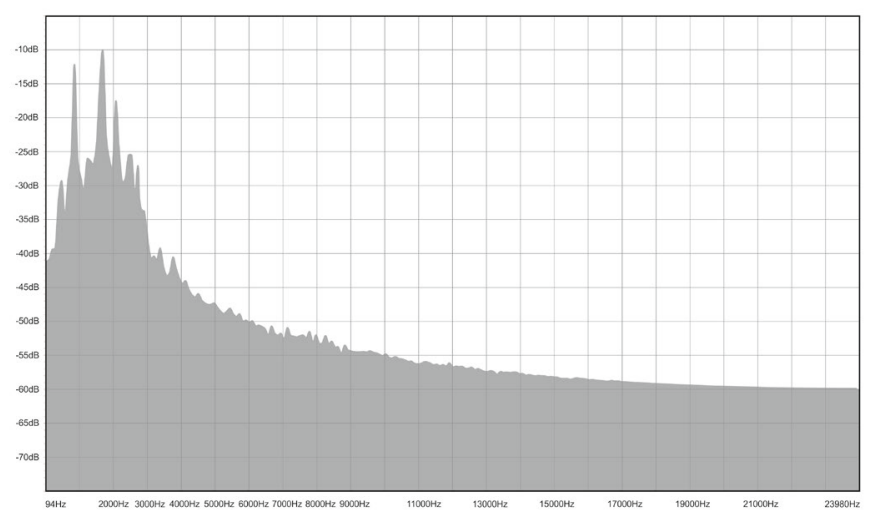

Figure 6. Frequency analysis of the sample of the original sound.

For the audio processing, the same audio sample of 10 seconds of duration was taken. This sample was used to analyze the harmonics and the fundamental frequencies. In addition, the selected fragment was remarkable for the study because it contained all the significant variables. The audio fragment was processed with one of the algorithms of the audio processing software, which provides the conversion of the temporal domain to the frequency domain. This algorithm applies the discrete Fourier transform to the sound sample. This operation results in a signal in which each frequency component has a weight or amplitude and a phase, this signal is called the frequency spectrum of the audio signal.

The bandwidth of a signal is defined by its maximum and minimum frequency components, so if a signal has frequencies from $0 \mathrm{~Hz}$ to $10 \mathrm{kHz}$, its bandwidth is $10 \mathrm{kHz}$, if the signal has components between $2 \mathrm{kHz}$ and $5 \mathrm{kHz}$, its bandwidth is $3 \mathrm{kHz}$. The presented signals range from $0 \mathrm{kHz}$ to $24 \mathrm{kHz}$.

\section{RESULTS AND DISCUSSION}

Of all the analysed samples, the most significant were those performed in PLA and even more those that had metallic additives to the main material. In relation to the sound recorded with the ABS sample (Figure 7), we observed that both high and low frequencies were lost, as well as the records presented less harmonics than the prototypes in PLA + Bronze, or PLA + Copper.

And within the graphs related to PLA + 00 (Figure 8), PLA + Bronze (Figure 9), or PLA + Copper (Figure 10), it is the last one that shows not only a greater spectral amplitude, with a greater number of components in all ranges, but also a higher resemblance to the original record. On the contrary, in the graph of the horn made with plain PLA, the frequency spectrum moves away from the spectrum of the original sound, thus emitting another type of sound with a limited and attenuated spectrum.

This result is expected, since the sonority of a musical instrument: its main frequency, its range of harmonics or its dynamics, is determined by many factors, including the material from which it is manufactured. In the case of a phonograph, which is not a musical instrument but a reproduction equipment, the quality of that reproduction also depends on many factors, one of which, and not the least important, is the structure and material of its horn. Traditionally these horns were made of brass, a metallic alloy of copper and zinc. The PLA + Copper material has a higher copper percentage than the PLA + Bronze, the results obtained with PLA+Copper were closer to those of the original sound. The prototypes in PLA, or ABS, being softer materials and plastics, absorb the acoustic waves, with the effect of spectral limitation, loss of harmonics and low overall sonority.

\section{CONCLUSIÓN}

It is evident that the assets that make up our heritage and more specifically our industrial heritage have a set of values that make them unique pieces. These objects have a clear interest in both their aesthetic part and in their technical innovation. Neverthless, they are complex objects, since their Kunstwollen capacity becomes a value to preserve. Therefore, in this type of objects, from a museologic approach, both its aesthetic appearance and its functionality must be preserved. In this case study, the phonograph keeps that memory capacity in his characteristic sound record. This feature has made it a reference object in the history of technology. 
Through this theoretical foundation, we have been able to verify that current technology, and in particular the reproduction of missing materials by $3 \mathrm{D}$ printing, is a good possibility. We think, as indicated by Zoran (1011), that the potential of 3D printing is beyond a standard and can solve what traditional manufacturing cannot.

Currently, and thanks to the versatility of the materials used in 3D printing, we have been able to propose a conceptual model that becomes specific for the creation of the missing part of the case study. The use of a filament with additives gives a prototype that offers a sound record closer to the original sound. The analysis made in this work proves that the results obtained with PLA + Copper horn were the closest to the original sound record. However, it did not generate the same frequency spectrum as the original horn, which is composed of an alloy, such as brass.

Likewise, the work opens a series of future lines of research. These lines may observe the results obtained with new 3D printing materials such as PolyJet, sintered nylon, or sintered metal among others. As a main conclusion, this proof of concept shows the integration of this technology with innovative restoration processes, characterized by a reversible and noninvasive approach.

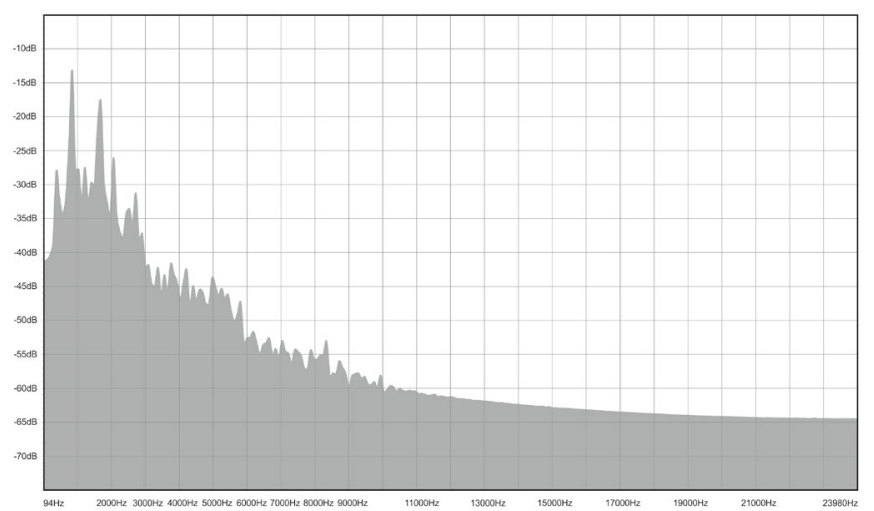

Figure 7. Frequency analysis of the sound sample with the prototype printed in $A B S$.

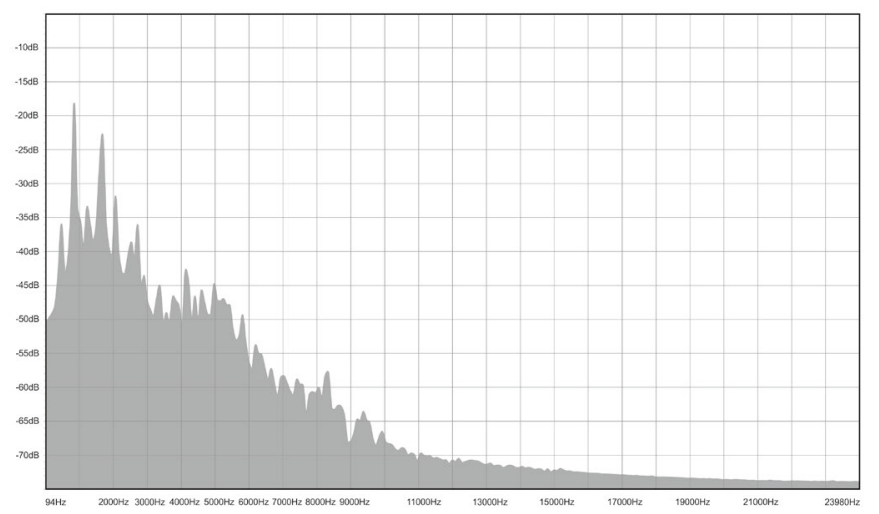

Figure 8. Frequency analysis of the sound sample with the prototype printed in PLA.

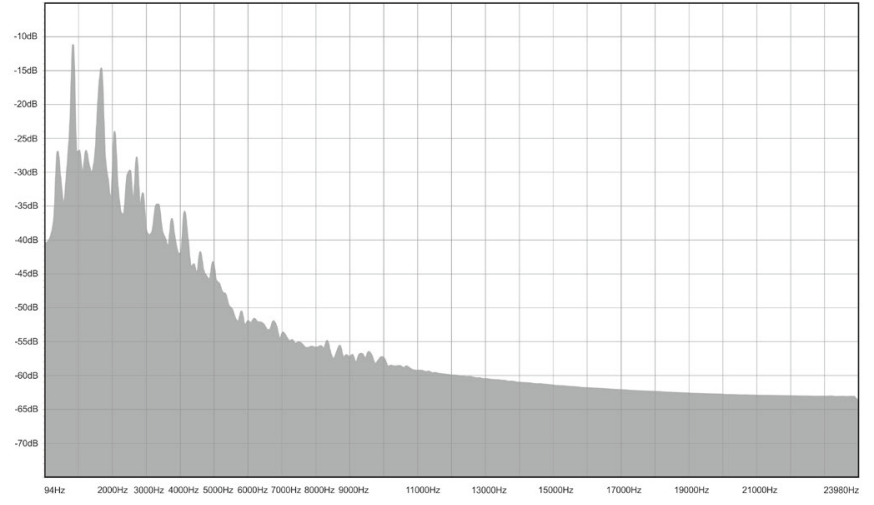

Figure 9. Frequency analysis of the sound sample with the prototype printed in PLA + Bronze.

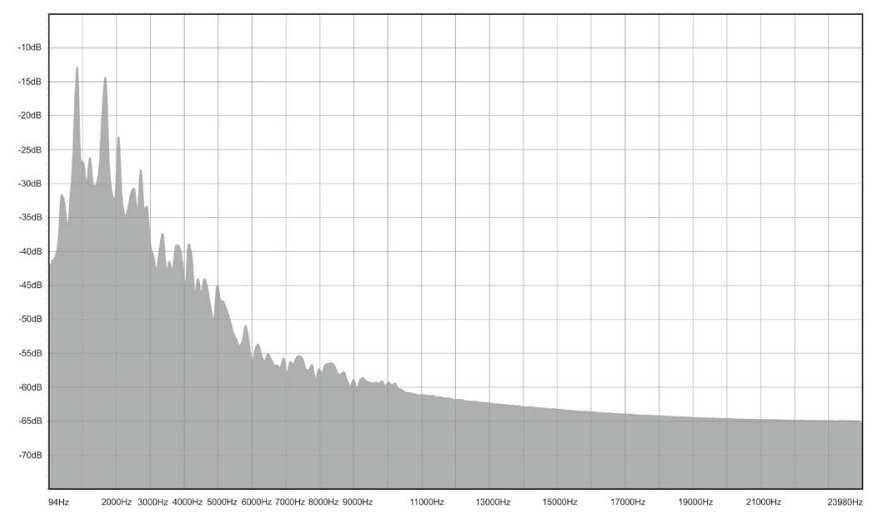

Figure 10. Frequency analysis of the sound sample with the prototype printed in PLA + Copper.

\section{ACKNOWLEDGMENTS}

The authors wan to acknowledge the support of the Museum of Telecommunication 'Vicente Miralles Segarra' and the Recording Studio of the E.T.S.I. Telecommunication of Universitat Politècnica de València.

\section{REFERENCES}

Alemanno, G., Cignoni, P., Pietroni, N., Ponchio, F., and Scopigno R., 'Interlocking pieces for printing tangible cultural heritage replicas', 12th Eurographics Workshops on Graphics and Cultural Heritage (EG GCH 2014), ed, R. Klein and P. Santos, Eurographics Association, (2014) 145-154.

Arrhenius, T., 'The Fragile Monument: On Alois Riegl's Modern Cult of Monuments', n.d. Nordisk Arkitekturforskning; Nordic Journal of Architectural Research, ed. Nordic Association of Architectural Research (2010) 51-55

Bachiller, C., Romero, M. D., Los inicios de la telecomunicación en la Comunidad Valenciana: Una publicación del Museo de la Telecomunicación 'Vicente Miralles Segarra'. Univeristat Politècnicas de València (2016).

Barassi, S., 'The Modern Cult of Replicas: A Rieglian Analysis of Values in Replication', Tate Papers 8 (Autumn 2007), http://www.tate.org.uk/research/publications/tate- 
papers/08/the-modern-cult-of-replicas-a-rieglian-analysis-ofvalues-in-replication, accessed 18 January 2018.

Brandi, C., Teoría de la Restauración, Alianza Editorial, Madrid (2000).

Celani, G., Cancherini, L., Jardini, A., Oliveira, M., Lopes da Silva, J., and Piccoli, V., '3D digitation of museum sculptures for model-making purposes: difficulties and possible solutions', Anais do V RAP, Rio de Janeiro (2009).

D’Urso, P.S., Thompson, R.G., and Earwaker, W.J., 'Stereolithographic (SL) biomodelling in palaeontology: a technical note', Rapid Prototyping Journal 6 (3) (2000) 212216.

Fantini, M., De Crescenzio, F., Persiani, F., Benazzi, and S., Gruppioni, G., '3D restitution, restoration and prototyping of a medieval damaged skull'. Rapid Prototyping Journal 14 (2008) 318-324.

Haśan, M., Fuchs, M., Matusik, W., Pfister, H., and Rusinkiewicz, S., 'Physical reproduction of materials with specified subsurface scattering', ACM Transactions on Graphics 29(4) (2010) 61:1-61:10.

Koumartzis, N., Tzetzis, P., and Kotsakis, R.G., 'A New Music Instrument from Ancient Times: Modern Reconstruction of the Greek Lyre of Hermes using 3D Laser Scanning, Advanced Computer Aided Design and Audio Analysis', Journal of New Music Research 44 (2015) 324-346

Lan, Y., Dong, Y., Pellacini, F., and Tong, X., 'Bi-scale appearance fabrication', ACM Transactions on Graphics 32(4) (2013) 145:1-145:12.

Levent, N., and Pascual-Leone, A., The Multisensory Museum: Cross-Disciplinary Perspectives on Touch, Sound, Smell, Memory, and Space. Rowman \& Littlefield, Maryland (2014).

Levin, A., Glasner, D., Xiong, Y., Durand, F., Freeman, W., Matusik, W., and Zickler T., 'Fabricating brdfs at high spatial resolution using wave optics', ACM Transactions on Graphics 32(4) (2013) 144:1-144:14.

Matusik, W., Ajdin, B., Gu, J., Lawrence, J., Lensch, H. P. A., Pellacini, F., and Rusinkiewicz, S., 'Printing spatially-varying reflectance', ACM Transactions on Graphics 28(5) (2009) 128:1-128:9.

Molés, V., Aplicaciones de audio en la nube para el Museo de la Telecomunicación "Vicente Miralles" (Audio on the cloud), Publicación Museo de las Telecomunicaciones UPV, Valencia (2016).

Muñoz, S., Teoría contemporánea de la Restauración, Síntesis, Madrid (2003).

Panozzo, D., Diamanti, O., Paris, S., Tarini, M., Sorkine, E., and Sorkine-Hornung, O., 'Texture mapping real-world objects with hydrographics', Computer Graphics Forum (SGP 2015) 34(5) (2015). http://vcg.isti.cnr.it/Publications/ 2015/PDPTSS15.

Papas, M., Regg, C., Jarosz, W., Bickel, B., Jackson, P., Matusik, W., Marschner, S., and Gross, M., 'Fabricating translucent materials using continuous pigment mixtures', $A C M$ Transactions on Graphics 32(4) (2013) 146:1-146:12.

Pérès, F., Taha, F., Lumley, M.A. and Cabanis, E., 'Digital modelling and stereolithographic production of a homo erectus skull', Rapid Prototyping Journal, 10(4) (2004) 247-254.

Pitzalis, D., Cignoni, P., Menu, M., and Aitken, G., ‘3D enhanced model from multiple data sources for the analysis of the cylinder seal of ibni-sharrum', The 9th International Symposium on VAST International Symposium on Virtual Reality, Archaeology and Cultural Heritage, Eurographics, Germany (2008) 79-84.

Pop, A., 'Why Alois Riegl Still Haunts Art History', Oxford Art Journal 38(2) (2015) 25-30.

Riegl, A., El culto moderno a los monumentos, Visor, Madrid (1999).

Rouiller, O., Bickel, B., Kautz, J., Matusik, W., and Alexa, M., '3D-printing spatially varying BRDFs', IEEE Computer Graphics and Applications 33(6) (2009) 48-57.

Scopigno, R., 'Gestione efficiente dei dati prodotti dai sistemi di scansione tridimensionale', Laser Scanner e GPS: Paesaggi Archeologici e Tecnologie Digitali 4 (2005) 41-68.

Scopigno, R., Cignoni, P., Pietroni, N., Callieri, M. and Dellepiane, M., 'Digital Fabrication Techniques for Cultural Heritage: A Survey', Computer Graphics Forum 36 (2017) 621.

Simon, N., The participatory museum. Museum 2.0 (2010) Creative Commons.

Styliani, S., Fotis, L., Kostas, K., and Petros, P., 'Virtual museums, a survey and some issues for consideration' Journal of Cultural Heritage 10(4) (2009) 520-528.

Weyrich, T., Peers, P., Matusik, W., and Rusinkiewicz, S., 'Fabricating microgeometry for custom surface reflectance', ACM Transactions on Graphics 28(3) (2009) 32:1-32:6.

Zhang, G., Tsou, Y., and Rosenberger, A.L., 'Reconstruction of the homunculus skull using a combined scanning and stereolithography processes, Rapid Prototyping Journal 6(4) (2000) 267-275.

Zhang, Y., Yin, C., Zheng, C., and Zhou, K., 'Computational hydrographic printing', ACM Transactions on Graphics (Proceedings of SIGGRAPH 2015) 34(4) (2015). http://www.cs.columbia.edu/cg/hydrographics.

Zoran, A., 'The 3D Printed Flute: Digital Fabrication and Design of Musical Instruments', Journal of New Music Research 40 (2011) 379-387. 